Basrah Journal Of Surgery

\section{SEPTOPLASTY WITH OR WITHOUT ANTERIOR NASAL PACKING}

\author{
Isam M Al-Shareda* \& Ghanem Sikhi Ghanem ${ }^{\#}$
}

*MBChB, FICMS, Assist. Prof. of Otolaryngology, Dept. of Surgery, College of Medicine, Basrah University. "MB,ChB, CABS, Basrah General Hospital, Basrah, IRAQ.

\begin{abstract}
Nasal packing is carried out in many nasal surgeries specially in septoplasty for hemostasis and internal stabilization of the cartilaginous \& bony skeleton of the nose. However, these packing methods are not a harmless procedures and for this reason their benefit has been tested.

The study was performed to compare the use of plastic intranasal splints with or without anterior nasal packing to determine the need of nasal packing after septoplasty.

This is a prospective comparative study which was carried out in Basrah General Hospital, Otolaryngology Department, Basrah, Iraq in the period from July 2014 to April 2015.

Forty seven patients of different age and gender groups were included in the study. Analysis was done regarding their history and examination including nasendoscopy which was done before septoplasty. The patients were randomly selected at the end of the procedure into two groups; one had plastic intranasal splints without anterior packing and the other had plastic intranasal splints with two different types of packing materials (ribbon gauze impregnated with Vaseline and glove fingers). Patients were compared for postoperative pain, headache, discomfort, bleeding, sleep difficulty, epiphora, septal hematoma on the day of the operation, 24 hours and 48 hours postoperatively. The collected data was analyzed by using SPSS v.17.

The age of patients in this study ranged from 18 to 44 years with mean age of $(29.6 \pm 6.2)$ years and most of them were between 28 to 37 years (48.9\%). Among those 47 patients, 28 (59.6\%) were males and 19 (40.4\%) were females with male:female ratio was 1.47:1.

Pain, headache, discomfort and bleeding was higher in patients in group two with anterior nasal packing materials especially during removal of the packing. there was significant reduction in the frequency of sleep disturbance, epiphora among the patients in group one without nasal packing, however there was no significant difference in septal hematoma between two groups. In conclusion, the plastic intranasal splints can be used alone without the need of anterior nasal packing materials after septoplasty as it can be considered as a type of packing methods that offers the advantages of elimination of pain and discomfort and reduce the complications of packing. The anterior nasal packing should be reserved only for selected cases.
\end{abstract}

\section{Introduction}

Tasal packing is used mainly to surgery and for internal stabilization of the cartilaginous and bony skeleton of the nose following septoplasty. Packing is thought to prevent complications of septal surgery. However, the nasal packing is not a safe procedure; it may cause some postoperative effects such as pain, discomfort and trauma to the nasal mucosa $^{1,2}$. The most common nasal packing materials are Telfa, paraffin gauze, Vaseline gauze, bismuth iodoform paraffin paste, glove fingers, silastic Merocel and gauze impregnated with different antibiotics ${ }^{3}$. Some surgeons who use packing in septoplasty remove it one day following surgery, others remove it five days postoperatively ${ }^{4}$. To avoid nasal packing, many researchers have successfully tried alternatives to traditional packing methods like pneumatic balloons left in place for various amounts of time, through and through mattress sutures to approximate two mucosal septal flaps and septal splints $^{2}$. sheets, Oxycel, Surgicel, Gelfoam, 


\section{Patients and methods}

This is a prospective comparative clinical study which was performed in Basrah General Hospital, Otolaryngology Department from July 2014 to April 2015. The study included patients who underwent septoplasty for nasal obstruction secondary to deviated nasal septum. The exclusion criteria were, patients who suffered from medical problems, those who were submitted to revision nasal surgeries, those who had other associated nasal pathology (e.g. nasal polyposis, turbinate hypertrophy) and those who needed anterior nasal pack at the end of the procedure due to uncontrolled bleeding. Patients were admitted to the Otolaryngology ward and preoperative assessment was done including history, general examinations in addition to thorough ENT examination including nasendoscopy.

This study included 47 patients with different age groups ranging from 18 to 44 years. Patients underwent septoplasty and were randomly assigned using research randomizer program, into two groups:

Group one: included 25 patients (53\%) who had plastic intranasal splints without anterior nasal packing(fig.1.a).

Group two: included 22 patients (47\%) who had plastic intranasal splints with anterior nasal packing which was also randomly selected according to the type of packing used into: 12 patients (26\%) had Ribbon gauze impregnated with Vaseline pack, 10 patients (21\%) had Glove fingers pack.

The type of nasal packing materials (Fig.1a, b and c) used for these patients was randomly selected using the same randomizing program, into either ribbon gauze $(2.5 \mathrm{~cm})$ impregnated with Vaseline petroleum jelly or glove fingers pack .

(A)

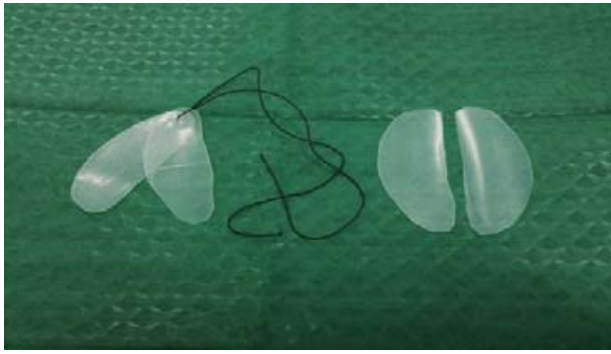

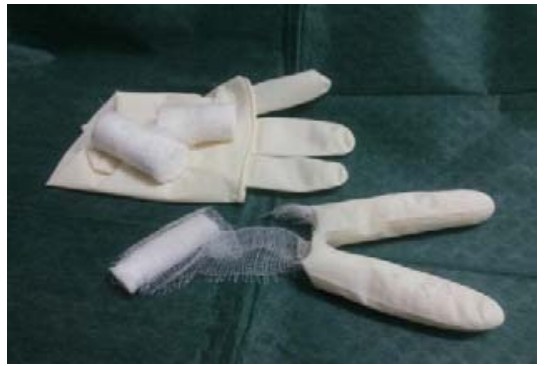

(B)

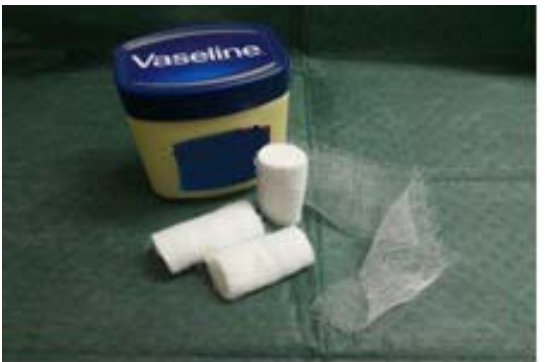

(C)

Figure 1: A:Plastic intranasal splints. B:Glove fingers pack. C:Ribbon gauze impregnated with Vaseline pack.

Patients were assessed postoperatively using questionnaire for the following parameters: discomfort, pain, headache based on the Visual Analogue Scale. Bleeding based on the severity and the intervention needed following Badr H.S. ${ }^{5}$ into: mild, moderate and severe. Other parameters such as sleep difficulty, disturbance, epiphora and septal hematoma were also evaluated. The data was collected on the day of operation, 24 hours and 48 hours postoperatively. Regarding patients in group two with anterior nasal packing, the packs were 
removed after 24 hours. The intranasal splints were removed after seven days. The results of the collected data were statistically analyzed using the SPSS version 17.0 considering that a $\mathrm{P}$ value $<$ 0.05 is statistically significant.

\section{Results}

A total number of 47 patients were included in the study. All patients underwent septoplasty and were randomly selected into two groups as shown in Fig.2.

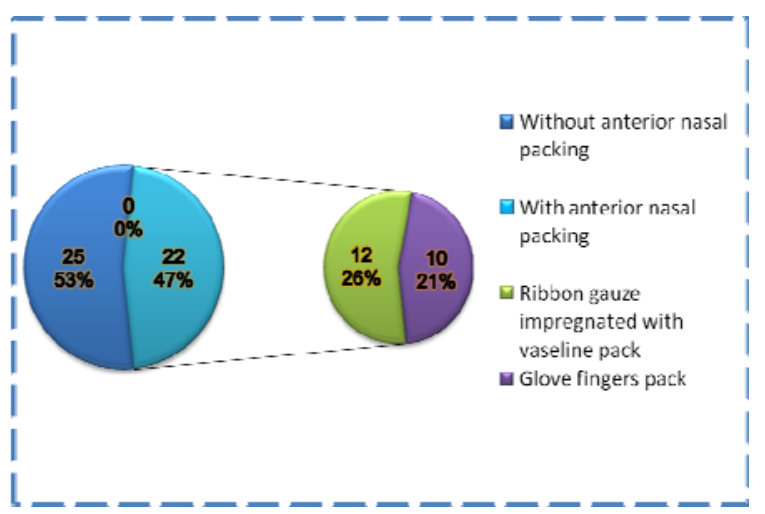

Figure 2: Allocation of patients into two groups.

The main complaint of all patients was nasal obstruction but some patients had additional symptoms like headache (8 patients), epistaxis (5 patients), postnasal discharge (4 patients) and snoring (3 patients). Most of the patients were males (28 patients, 59.6\%) and 19 patients (40.4\%) were females. The age of the studied patients ranged from 18 to 44

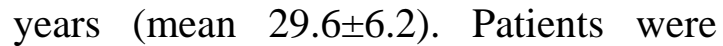
distributed into three age categories and the distribution of gender among the age categories is shown in (Fig.3). The majority of the patients were between 2837 years (48.9\%) and 18-27 years (36.2\%) of age. The remaining patients (14.9\%) were between $38-47$ years as shown in fig.3.

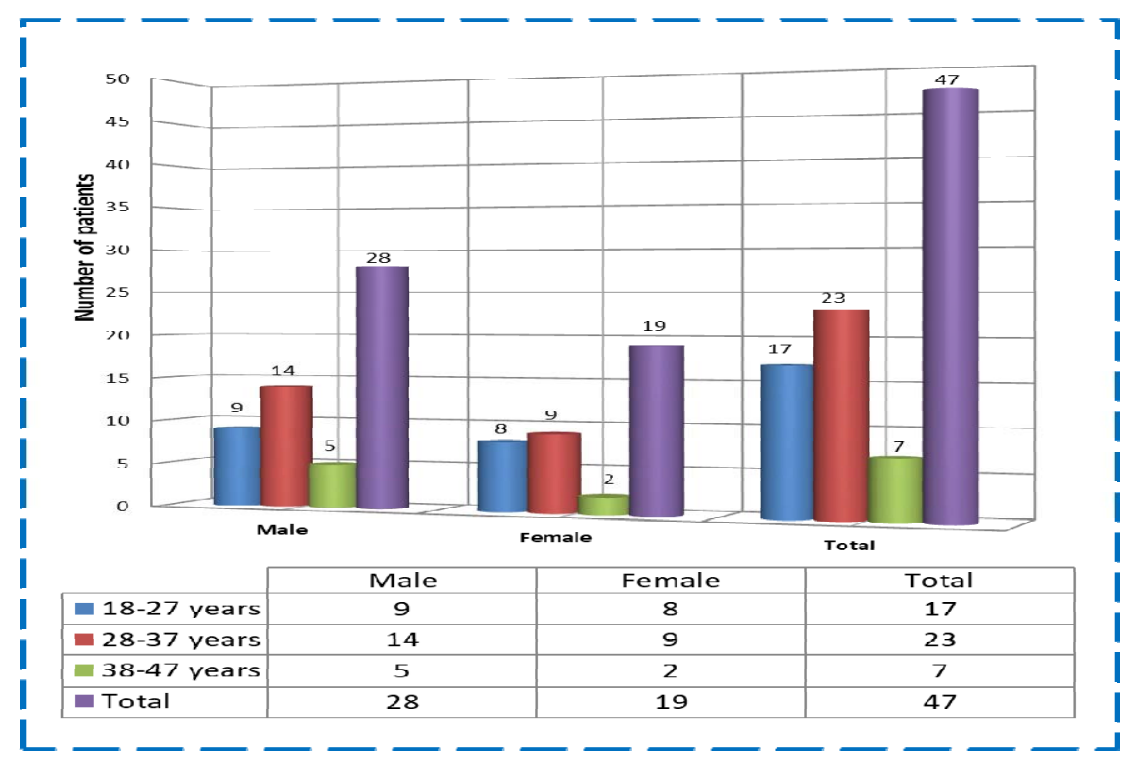

Figure 3: Age and gender distribution.

The severity of the pain was measured by using the visual analog scoring system on the operative day, first and second days postoperatively. The following tables show the results of different parameters measured during this study. 
Table I: Postoperative pain, headache and discomfort on the day of the operation.

\begin{tabular}{|c|c|c|c|c|c|}
\hline \multirow[t]{2}{*}{ Pain severity } & \multirow[t]{2}{*}{$\begin{array}{c}\text { Group one } \\
\text { without packing }\end{array}$} & \multirow[t]{2}{*}{$\%$} & \multicolumn{2}{|c|}{$\begin{array}{l}\text { Group two } \\
\text { with nasal packing }\end{array}$} & \multirow[t]{2}{*}{$\%$} \\
\hline & & & Ribbon gauze & Glove fingers & \\
\hline No pain & 0 & 0 & 0 & 0 & 0 \\
\hline Mild & 22 & 88 & 1 & 3 & 18.3 \\
\hline Moderate & 3 & 12 & 8 & 7 & 68.1 \\
\hline Severe & 0 & 0 & 3 & 0 & 13.6 \\
\hline Total & 25 & 100 & 12 & 10 & 100 \\
\hline
\end{tabular}

$P$ value (group one and two $)=0.000 . P$ value $($ ribbon gauze and glove fingers packs $)=0.134$

Table II: Postoperative pain, headache and discomfort on the first day.

\begin{tabular}{|c|c|c|c|c|c|}
\hline \multirow{2}{*}{ Pain severity } & $\begin{array}{c}\text { Group one } \\
\text { without packing }\end{array}$ & $\%$ & \multicolumn{2}{|c|}{$\begin{array}{c}\text { Group two } \\
\text { with nasal packing }\end{array}$} & \multirow{2}{*}{$\%$} \\
\cline { 3 - 5 } & & & Ribbon gauze & Glove fingers & \\
\hline No pain & 0 & 0 & 0 & 0 & 0 \\
\hline Mild & 23 & 92 & 0 & 1 & 4.6 \\
\hline Moderate & 2 & 8 & 2 & 9 & 50 \\
\hline Severe & 0 & 0 & 10 & 0 & 45.4 \\
\hline Total & 25 & 100 & 12 & 10 & 100 \\
\hline
\end{tabular}

$P$ value (group one and two) $=0.000 . P$ value (ribbon gauze and glove fingers packs) $=0.000$

Note: The severity of pain in group two was measured during removal of packing.

Table III: Postoperative pain, headache and discomfort on the second day.

\begin{tabular}{|l|l|l|l|l|l|}
\cline { 1 - 1 } Pain & $\begin{array}{l}\text { Group one } \\
\text { without packing }\end{array}$ & \multirow{2}{*}{$\begin{array}{l}\text { Group two } \\
\text { with anterior nasal packing) }\end{array}$} & $\%$ \\
\cline { 1 - 4 } & & Ribbon gauze & Glove fingers & \\
\hline No pain & 0 & 0 & 0 & 0 & 0 \\
\hline Mild & 25 & 100 & 12 & 10 & 100 \\
\hline Moderate & 0 & 0 & 0 & 0 & 0 \\
\hline Severe & 0 & 0 & 0 & 0 & 0 \\
\hline Total & 25 & 100 & 12 & 10 & 100 \\
\hline
\end{tabular}

$P$ value $=1.000$

The severity of the bleeding among patients are shown in the following tables:

Table IV: Postoperative bleeding on the day of the operation.

\begin{tabular}{|c|c|c|c|c|c|}
\hline \multirow{2}{*}{$\begin{array}{c}\text { Bleeding } \\
\text { severity }\end{array}$} & $\begin{array}{c}\text { Group one } \\
\text { without packing }\end{array}$ & $\%$ & \multicolumn{2}{|c|}{$\begin{array}{c}\text { Group two with } \\
\text { anterior nasal packing }\end{array}$} & \multirow{2}{*}{$\%$} \\
\cline { 4 - 6 } & & & Ribbon gauze & Glove fingers & \\
\hline Mild & 21 & 84 & 11 & 10 & 91.7 \\
\hline Moderate & 4 & 16 & 1 & 0 & 8.3 \\
\hline Severe & 0 & 0 & 0 & 0 & 0 \\
\hline Total & 25 & 100 & 12 & 10 & 100 \\
\hline
\end{tabular}

$P$ value (group one and two $)=0.370 . P$ value $($ ribbon gauze and glove fingers packs $)=0.776$

Table V: Postoperative bleeding on the first day.

\begin{tabular}{|l|l|l|l|l|l|}
\hline $\begin{array}{l}\text { Bleeding } \\
\text { severity }\end{array}$ & $\begin{array}{l}\text { Group one } \\
\text { Without packing }\end{array}$ & $\%$ & \multicolumn{2}{|l|}{$\begin{array}{l}\text { Group two with } \\
\text { anterior nasal packing }\end{array}$} & $\%$ \\
\cline { 1 - 5 } & Ribbon gauze & Glove fingers & \\
\hline Mild & 23 & 92 & 3 & 8 & 50 \\
\hline Moderate & 2 & 8 & 9 & 2 & 50 \\
\hline Severe & 0 & 0 & 0 & 0 & 0 \\
\hline Total & 25 & 100 & 12 & 10 & 100 \\
\hline
\end{tabular}


$P$ value (group one and ribbon gauze packing) $=0.000 . P$ value (group one and glove fingers packs $)=0.612 . P$ value (ribbon gauze and glove fingers packs $)=0.013$

Note: the severity of the bleeding in group two was observed during removal of packing.

Table VI: Postoperative bleeding on the second day.

\begin{tabular}{|l|l|l|l|l|l|}
\hline bleeding severity & $\begin{array}{l}\text { Group one } \\
\text { without packing }\end{array}$ & $\%$ & \multicolumn{2}{|l|}{$\begin{array}{l}\text { Group two with } \\
\text { anterior nasal packing }\end{array}$} & $\%$ \\
\cline { 3 - 6 } & 25 & 100 & 12 & 10 & 100 \\
\hline Mild & 0 & 0 & 0 & 0 & 0 \\
\hline Moderate & 0 & 0 & 0 & 0 & 0 \\
\hline Severe & 25 & 100 & 12 & 10 & 100 \\
\hline Total & & & & Glove fingers & \\
\hline
\end{tabular}

$P$ value $=1.000$

The effects of nasal packing on the both sleep disturbance and difficulty is shown in the following table

Table VII: Sleep disturbance \& difficulty in two groups of patients.

\begin{tabular}{|l|l|l|l|l|l|}
\hline \multirow{2}{*}{ Time } & $\begin{array}{l}\text { Group one } \\
\text { Without packing }\end{array}$ & $\%$ & \multicolumn{2}{|l|}{$\begin{array}{l}\text { Group two With } \\
\text { anterior nasal packing }\end{array}$} & $\%$ \\
\cline { 3 - 5 } & & Ribbon gauze & Glove fingers & \\
\hline Operation Day & 8 & 32 & 10 & 8 & 81.8 \\
\hline 1st day postoperative & 0 & 0 & 2 & 1 & 13.6 \\
\hline 2nd day postoperative & 0 & 0 & 0 & 0 & 0 \\
\hline
\end{tabular}

Day of the operation : $P$ value (group one and two) $=0.000 . P$ value (ribbon gauze and glove fingers packs $)=0.820$. 1 st day postoperative: $P$ value $=0.313$. 2 nd day postoperative: $P$ value $=1$ The incidence of epiphora among patients in the two groups is shown in table VIII

Table VIII: The incidence of epiphora

\begin{tabular}{|l|l|l|l|l|l|}
\hline \multirow{2}{*}{ Time } & $\begin{array}{l}\text { Group one } \\
\text { Without packing }\end{array}$ & $\%$ & \multicolumn{2}{l}{$\begin{array}{l}\text { Group two with } \\
\text { anterior packing }\end{array}$} & $\%$ \\
\cline { 3 - 6 } & & Ribbon gauze & Glove fingers & \\
\hline Day of the operation & 3 & 12 & 8 & 4 & 54.5 \\
\hline 1st day postoperative & 0 & 0 & 1 & 0 & 4.5 \\
\hline 2nd day postoperative & 0 & 0 & 0 & 0 & 0 \\
\hline
\end{tabular}

Day of the operation: $P$ value (group one and two 0.001. $P$ value (ribbon gauze and glove fingers packs) $=0.331$. First day postoperative: $P$ value $=0.732$. Second day postoperative: $P$ value $=1.000$

Table XI shows the incidence of septal hematoma among patients in the two groups

Table IX: The incidence of septal haematoma.

\begin{tabular}{|c|c|c|}
\hline Time & $\begin{array}{c}\text { Group one } \\
\text { Without packing }\end{array}$ & $\begin{array}{c}\text { Group two with } \\
\text { anterior packing }\end{array}$ \\
\hline Day of the operation & 0 & 0 \\
\hline First day postoperative & 0 & 0 \\
\hline Second day postoperative & 0 & 0 \\
\hline
\end{tabular}

\section{Discussion}

$$
P \text { value }=1.000
$$

Septoplasty is one of the most common operations in routine otolaryngology practice, alone or in combination with other procedures. The unpleasant part of this procedure is the postoperative nasal packing ${ }^{6}$. There is no scientific evidence to support the benefit of nasal packing and no generally accepted standards regarding the materials that should be used for nasal packing, the indications for nasal packing and how long the packing should be left in place ${ }^{4,7}$. Nasal packing in septoplasty looks to be more routinely used than really required in every case 
but is still being practiced in most of the centers. It is done preventively for hemostasis or because of the fear from postoperative bleeding.

In this study as in many other studies ${ }^{8-}$

${ }^{11}$, there was a predominance of males than females. This distribution can be explained by that the incidence of deviated nasal septum is more in males than females because of trauma liability.

The age of the patients in this study ranged from 18 to 44 years as in other studies $^{9,12,13}$, this can be explained that this age group is more liable to trauma.

In the present study, the severity of postoperative pain, headache and discomfort on the day of operation was higher in group two with anterior nasal packing in which $81.7 \%(18 / 22)$ of patients had moderate to severe pain and only $18.3 \%(4 / 22)$ had a mild pain, in addition there was no much difference $(P=0.134)$ in the pain experienced among those patients who had different types of packing materials, while in group one without nasal packing the pain was mild in $88 \%(22 / 25)$ of the patients. On the first day postoperatively and during removal of packing (for patients in group two), severity of pain was very high (95.4\%, 21/22), most of them had moderate to severe pain specially in patients with ribbon gauze pack (83.3\%, 10/12). On the second day postoperatively there was no difference between the two groups. These results are similar to that found in the other studies $2,7,14-16$, who considered nasal packing especially during removal is an important clinical factor.

The present study shows that severity of postoperative bleeding on the day of the operation was mild in both groups $(P=0.370)$, only four patients $(16 \%)$ in group one without nasal packing and one patient (8.3\%) in group two had a moderate bleeding which required interventions either with light packing (cotton pledgets soaked with ointment) or reinsertion of new nasal packing. On the first day postoperatively, most of patients (75\%, 9/12) who had a ribbon gauze pack developed moderate bleeding during removal of packing than patients with glove fingers pack and patients which has mild bleeding in $(80 \%, 8 / 10)(P=0.013)$ and $(92 \%, 23 / 25)(P=0.000)$ respectively. Two patients in group one (which continue to have moderate bleeding after removal of the light pack that inserted the day before) and eleven patients in group two, needed light packing kept for few hours then discharged from the hospital. The second day postoperatively all patients had either no bleeding or mild bleeding. There was no severe bleeding in both groups of patients. These findings are similar to other studies ${ }^{7,15-19}$.

Regarding the sleep difficulty in this study; on the day of operation, it was greater in group two patients $(81.8 \%$, $18 / 22)$ than in group one $(32 \%, 8 / 25)$ $(P=0.000)$, same is for epiphora $(54.5 \%$, $12 / 22)$ and $(12 \%, 3 / 25)$ respectively $(P=0.001)$. There was no much difference $(P=0.820)$ in these complains among patients in group two who had different types of packing materials. After removal of nasal packing for patients in group two, there was no significant difference $(P=1.000)$ in the incidence of epiphora or sleep difficulty in both groups of patients on the first and second days postoperatively. The epiphora results from obstruction to the opening of the lacrimal duct and the sleep difficulty was due to pain, irritability and nasal occlusion that causes worsening in apnea and consequent frequent awakenings which was the same causes in other studies $^{7,14,20,21}$.

In this study, no patient had developed septal haematoma in both groups. This is in agreement with other studies $2,7,12,15,22$, that revealed no significant difference between two groups in the incidence of septal hematoma, but this result was against to Al-Raggad DK et $\mathrm{al}^{20}$ study who reported that four patients $(4.8 \%)$ of packing group developed septal 
hematoma which required evacuation, packing and hospitalization for 48 hours. Probably in our study because of insertion of plastic splint along with the anterior packing that provides extra pressure on the septum aid to prevent blood collection rather than using anterior packing alone.

Conclusions and recommendations: Postoperative intranasal packing material will not result in any further benefits to patients underwent septoplasty over the using of intranasal splints alone, therefore splints can be a good alternative for packing as it can be considered as a type of packing method. The advantages are: It offers less pain, headache and discomfort for the patients.

The frequency of bleeding is minimum after septoplasty and the need of anterior nasal packing for hemostasis is limited. It provides less sleep disturbance and epiphora especially on the night of the operation. The drawbacks is a slight risk of bleeding and septal hematoma during the day of the operation if no packing materials were used, although it was statically not significant.

The severity of pain was less when using the splints alone, but still there was some sort of pain and discomfort among the patients when they touch or clean the nose.

From this study, we recommend that the anterior nasal packing should be kept for those patients who had uncontrolled bleeding during surgery or those with reactionary bleeding or had developed septal hematoma. The type of the material should be that with least complications, which is in this case the glove fingers pack. Other methods can be tried to further minimized the complications of both splints and packing, like using a different types of packing materials for example silastic sheets, Oxycel, Surgicel, Gelfoam, Merocel and pneumatic balloons with ventilation tube or using trans-septum through and through suturing technique.

\section{References}

1. Price JC. Septoplasty. In: Johns ME; Price CP; Mattox DE, eds: atlas of head and neck surgery. Philadelphia: BC. Decker, 1990;1: 109-20.

2. Ardehali MM, Bastaninejad S. Use of nasal packs and intranasal septal splints following septoplasty. International Association Journal of Oral and Maxillofacial Surgery, 2009; 1609 :1-3.

3. Arvind KA, Omar B, Ajay N. Double-blind randomised controlled trial comparing Merocel with Rapid Rhino nasal packs after routine nasal surgery. Rhinology, 2003; 41: 241-243.

4. Lubianca JF, Sant'anna GD, Mauri M, Carlos AB. Evaluation of time of nasal packing after nasal surgery: a randomized trial. Otolaryngology Head and Neck surgery, 2000; 122: 899-901.

5. Friedman M, Vidyasagar R. Surgical Management of Septal Deformity, Turbinate Hypertrophy, Nasal Valve Collapse, and Choanal Atresia. In : Bailey, Byron J.; Johnson, Jonas T.; Newlands, Shawn D.(eds) Head \& Neck Surgery - Otolaryngology. $4^{\text {th }}$ Edition. Vol.1. Lippincott Williams and Wilkins, $2006: 323-326$.

6. Roblin DG, Eccles R. What, if any, is the value of septal surgery? Clinical Otolaryngology, 2002; 27:77-80.

7. Bitzer EM, Dorning H, Schwartz FW. Der klinische Erfolg der operativen Korrektur der Nasenscheidewand. Laryngorhinootologie, 1996; 75: 64959.

8. Ferguson BJ, Myers EN. Nose and paranasal sinuses. In : Operative Otolaryngology, Head and Neck Surgery. 2 ${ }^{\text {nd }}$ Edition. Elsevier Inc. 2010:29-44. 9. Charles AE. Septoplasty and repair of septal perforation. In : Bleach N, Milford C, Van-Hasselt A. Operative Otorhinolaryngology. $1^{\text {st }}$ Edition. Blackwell Science Ltd 1997:173-180.

10.Siegel NS, Gliklich RE, Taghizadeh F, Chang Y. Outcomes of septoplasty. Otolaryngology, Head and Neck Surgery, February 2000;122(2):228-32. 11. Samad I, Stevens HE, Maloney A. The efficacy of nasal septal surgery. Journal of Otolaryngology, April 1992;21(2):88-91.

12. Binghan BJG, Hawthorne MR. synopsis of operative ENT surgery. Butterworth-Heinemann Oxford, 1992:171-177.

13. Badr H.S. Nasal septum suturing versus nasal packing after septoplasty : a prospective study. Thesis submitted to the scientific council of Otolaryngology, Iraqi Commission for Medical Specialization in Otolaryngology, 2009; (3) :30.

14. Muhammad H, Inayatullah, Iqbal K, Zakirullah. Septoplasty without nasal packing. Gomal Journal of Medical Sciences, July-December 2010; Vol.8, No. $2: 141-142$.

15. Bernardo MT, Alves S, Lima NB, Helena D, Condé A. Septoplasty with or without postoperative nasal packing? Prospective study. Brazil journal of Otorhinolaryngology, São Paulo, June/Aug. 2013; Vol.79, No.4.

16. Kazkayasi M, Dinçer C, Arikan OK, Kiliç R. The effect of nasal packing and suture technique on systemic oxygen saturation and patient comfort after septoplasty. Kulak Burun Bogaz Ihtis Derg., 2007;17 (6):318-323.

17. Al-Mazrou KA, Zakzouk SM. The impact of using intranasal splints on morbidity and prevalence of adhesions. Saudi Medical Journal, 2001; Vol.22(7):616-618.

18. Prayaga N., Moorthy S, Kolloju S, Madhira S, Ali BJ. Clinical Study on Deviated Nasal Septum and Its Associated Pathology. International Journal of Otolaryngology , Head \& Neck Surgery, 2014; 3: 75-81.

19. Nayak DR, Balakrishnan R, Deepak MK. Produl Hazarika. Indian Journal of Otolaryngology, Head and Neck Surgery, $2002 ; 54: 20-24$.

20. Al-Raggad DK, El-Jundi AM, Al-Momani OS, Al-Serhan MM, Nawasrah OO, Qhawi MA, Husban AM. Suturing of nasal septum after septoplasty: is it an effective alternative to nasal packing? Saudi Medical Journal, 2007; 28(10):1534-1536.

21. PriyoSakhi D, Bhutia TJ, Lyngdoh N, Kumar S, Bhutia NN, Babu P. A comparative study of septoplasty with and without nasal packing. National Journal of Otorhinolaryngology, Head and Neck Surgery, August 2014; Vol. 2(11), No. 2.

22. Awan MS, Iqbal M. Nasal packing after septoplasty: a randomized comparison of packing versus no packing in 88 patients. Journal of Ear, Nose and Throat, 2008; 87(11):624-627. 